Portland State University

PDXScholar

Engineering and Technology Management

Faculty Publications and Presentations

Engineering and Technology Management

$9-1-2016$

\title{
Understanding Risk Perception Using Fuzzy Cognitive Maps
}

\author{
Pei Zhang \\ Portland State University \\ Antoine J. Jetter \\ Portland State University, ajetter@pdx.edu
}

Follow this and additional works at: https://pdxscholar.library.pdx.edu/etm_fac

Part of the Operations Research, Systems Engineering and Industrial Engineering Commons Let us know how access to this document benefits you.

\section{Citation Details}

Zhang, Pei and Jetter, Antoine J., "Understanding Risk Perception Using Fuzzy Cognitive Maps" (2016). Engineering and Technology Management Faculty Publications and Presentations. 113.

https://pdxscholar.library.pdx.edu/etm_fac/113

This Article is brought to you for free and open access. It has been accepted for inclusion in Engineering and Technology Management Faculty Publications and Presentations by an authorized administrator of PDXScholar. Please contact us if we can make this document more accessible: pdxscholar@pdx.edu. 


\title{
Understanding Risk Perception Using Fuzzy Cognitive Maps
}

\author{
Pei Zhang, Antonie Jetter \\ Portland State University, Engineering and Technology Management Dept., Portland, OR 97207 USA
}

\begin{abstract}
When making decision that can have farresearching effects, such as governmental policies or decisions on new technologies, decision-makers use their understanding of the risks that are associated with their choices to guide their decisions. Measuring how people perceive risks can be helpful for understanding and possibly improving the decision-making process. Building on a review of existing methods for investigating risk perceptions, this paper suggests Fuzzy Cognitive Maps (FCM) as a method for investigating differences in risk perception among stakeholders and stakeholder groups. The approach is illustrated with an example of wildfire risk perceptions. Results suggest that FCM can contribute to risk perception studies and provide means to improve communications between different stakeholder groups and their involvement in the decision-making process.
\end{abstract}

\section{INTRODUCTION}

New technologies are not only perceived as a source of new opportunities but also raising concerns about risks. A case in point is the so-called Internet of Things (IoT), a global Internet-based technical architecture [1]which is driven by big data and cloud computing technologies and leads to the deployment of billions of interconnected devices. IoT technology raise concerns about the security and privacy of users and other stakeholders. Matters of concern are the architecture's resilience to attacks (or lack thereof), challenges around data authentication, access control and client privacy [1], [2] and technical risks such as sensor failure, insufficient computational capabilities, the possibility of network service failure [3], and database management problems [4]. The discussion of the resulting risks vulnerability of safety critical infrastructure to terrorist attacks, fear of government surveillance, behavioral profiling of individuals with criminal intent, loss of private data an fraud, etc. - highlights the need for new policies, decision guidelines, and strategic planning for the further development of IoT technologies. This will require the study of technology risks, as they are perceived by technical experts, lay public and policy makers. Past adoption patterns for new technology have shown the importance of understanding how the public and policy makers assess risks: In banking, customers' risk perception have had a negative impact on the adoption of mobile banking platforms [5]. Similarly, the study of online shopping as an emerging technology shows that consumers perception of the risks associated with online shopping, at least initially, have had a significantly negative influence on consumers" willingness shop online [6].

The study of risk perception dates back to the 1960s and was inspired by the observation that experts and lay people often differ in how they assess a hazard or man-made technical risks [7]: risks that technical experts consider to be low because they are unlikely to occur may still seem unacceptable to the public, based on "the meaning and value that is given to the outcome and consequences that depend on political, aesthetic and moral viewpoints" [8, pp27]. Thus, cognitive processes that determine perception and evaluation of risks are central aspects of 'modern' risk research [7]. Research in this field suggests that the understanding of risk perception is highly related to effective policy making [8]-[11]: Learning about what people are worried about and what can bring possible harms, is helpful for government policy makers to pursue new policies and protect the public from perceived risks [11].

More recent studies, after 2000, increasingly apply risk perception concepts outside government policy making, including offshore oil and gas operations [12], emerging technologies [13], [14],cloud computing [19], entrepreneurship [15], and construction project management [16]. These studies show that understanding how risks are perceived by different groups and from multiple perspectives can help technology management: If perceived risks are mainly determined by the technology itself, technology managers can take action, through research and development, to improve technologies in ways that reduce perceived risk. If perceived risks are high due to a misunderstanding of technologies, improved risk communications can improve public support and technology adoption, while also influencing policy makers to provide regulatory frameworks that are adequate for the actual risks. However, to date, risk perception studies are still mainly done by sociologists, decision researchers, and psychologists and only slowly increasing in the field of technology management. As a result, industry practitioners lack robust and practical approaches for the study of risk perception.

This paper gives a review on existed risk perception researches, related methodologies and their major findings. According to the existed risk research, there are gaps on how to include all parts of stakeholder groups into the risk perception study process, and how to leverage stakeholders' risk perceptions better for decision-making needs. Fuzzy Cognitive Maps (FCM) could provide a directly way to look into the cognitive patterns of stakeholder groups' risk perception and predict possible decision-making scenarios. Also, a case study of applying FCM into wildfire risk perception study will be provided for showing the approach of FCM.

\section{LITERATURE REVIEW ON RISK PERCEPTION}

\section{A. The development of Risk Perception Studies}

Studies of risk perception examine the opinions people express when they are asked to characterize and evaluate 
hazardous activities and technologies [8]. The topic rose to the attention of sociologists and decision researchers in the 1980s, when the strong public debate on nuclear power and nuclear weapons highlighted increased concerns about natural hazards and technological disasters. At the time, researchers were mainly focused at understanding, through psychometric surveys [17], [18], how people score the severity of different risks. This approach seemed well suited for identifying similarities and differences among groups with regard to risk perceptions and attitudes. [17] The research showed that the major risks of concern to the public were nuclear power, radiation, and chemical hazards [17], with nuclear power plants ranking highest. Research results impacted policies on governing nuclear power.

After understanding what general risks were assessed to be of higher or lower importance, the researchers became interested in analyzing what factors affect people's risk perception, risk assessment, and risk behaviors. Addressing these questions, Slovic and Sjoberg [19] built a framework for analyzing survey data that used a combination of techniques, including factor analysis [17] cluster analysis [19], and affect analysis [10]. In this period of study, nuclear power is still a hot topic as a case to test the research findings. Later studies also focused on air pollution [20], Egovernment services [21], food industry [22], and gene technology [23]. Across these research, several factors were identified to impact risk perception, namely regional characteristics, gender, and age [24], social trust, and knowledge. Among those factors related to trust [17], [20][22], [24] have been identified to be the most important. In these studies, participants were typically classified as lay public, technological experts and policy makers [8], [17] and differences in the risk perception between the lay public and experts have been detected and studied deeply.

More recent studies, after 2000, follow the same tradition but also investigate risk perception outside government policy making, including offshore oil and gas operations [12], emerging technologies [13], [14],cloud computing [19], entrepreneurship [15], and construction project management [16]. The work generally explores the following themes:

- Foundations of Risk Perception, covering the fundamental process that leads people to perceive something to be risky [8].

- Perception of Natural Hazards, including flood, air pollution, and climate change.

- Technological Risks, especially for emerging technologies at the time, including nuclear energy, gene technology, cloud computing, etc.

- Risk Behavior, including worker and construction safety, entrepreneurship, and gambling

The studies above continue to be grounded in basic cognitive psychology [17] and theories on group behavior [7] and, accordingly, are often undertaken by psychologists and sociologists, using methods commonly used in these fields. However, increasingly studies also occur in technology management. The focus of the studies are mainly individuals and groups, as well as trust in government institutions [22]. Accordingly, data collection occurs from individuals, groups, and on the national level. Table 1 summarizes the research themes.

TABLE 1: THEMES, DATA COLLECTION LEVEL, AND RESEARCHERS IN RISK PERCEPTION STUDIES

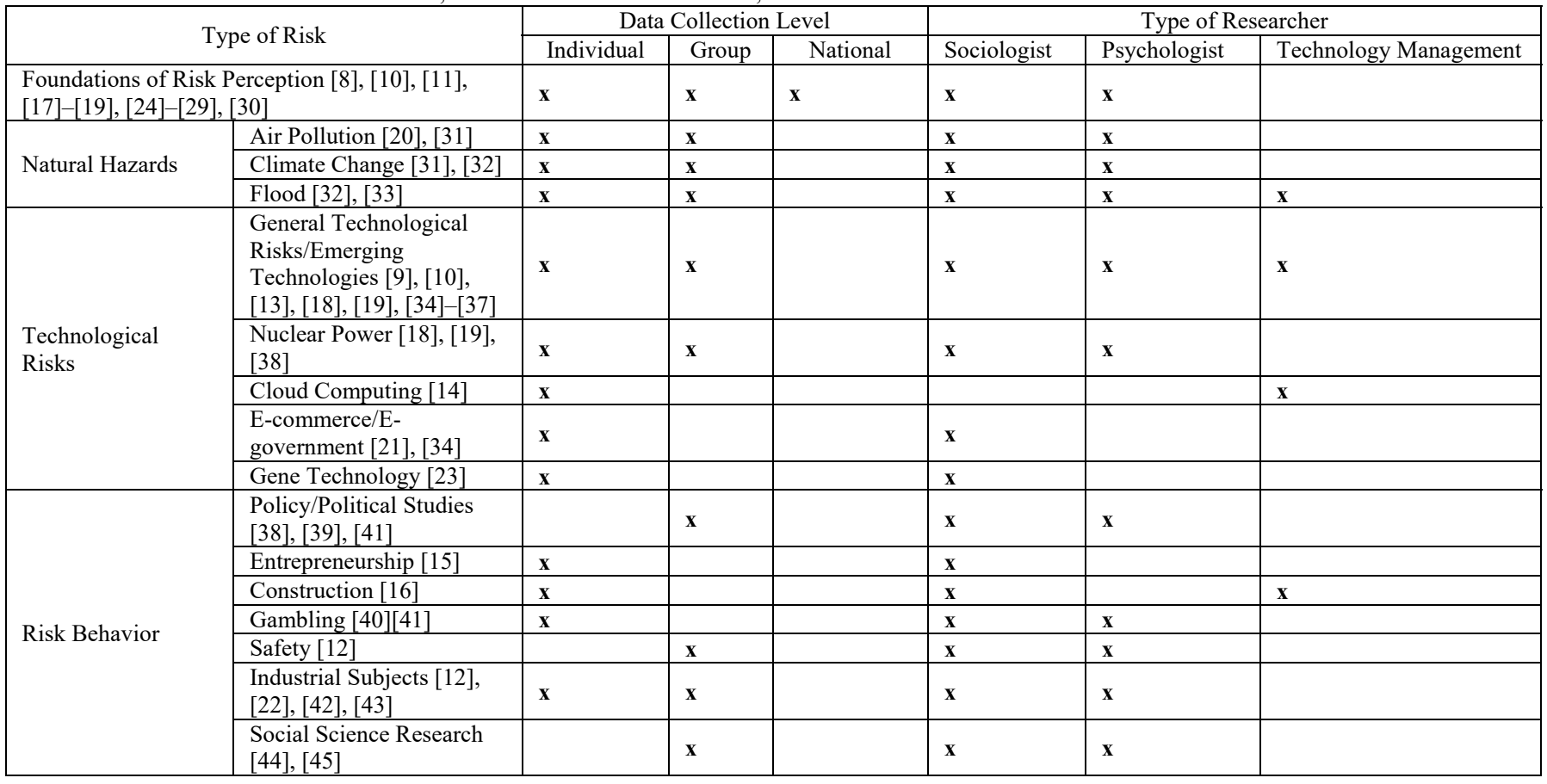




\section{B. Major Findings from the existing Risk Perception Studies}

Over 50 years of risk perception studies, as outlined in Table 1 above, have resulted in a number of findings that are summarized in the framework in Figure 1. The framework shows the three roles commonly assigned to research subjects in risk perception studies: the lay public, which is typically researched to identified how they perceive risk, the technology/risk experts who are asked to provide information on the level of 'real', objective risks, based on scientific assessments, and policy makers who take in information on perceived and objective risks for the purpose of making technology decisions and decisions on policies that govern technologies. Building a foundation of work in social studies, risk perception research operates at the intersection of these three groups by researching their differences in risk assessments, communicating findings, and, increasingly, developing methods for bringing the groups together.
The framework in Fig. 1 further highlights some of the major findings in risk perception research.

Risk perception studies are grounded in social studies. One of the most important goal of doing risk perception studies is serving the decision-making process for policy makers [17], [18]. By studying into people's risk perceptions, risk behaviors, and the social factors that would affect the perceived risks, the researchers provided valuable information to policy makers to create policies, improve risk communication, and lead to a better decision-making. The society is the general environment where people are perceiving risks, which make the connections between risk perception studies and social studies becoming stronger. New policies from policy makers make this connection stronger, which reflects the study results to the public through the way. But from the literature review, the policy maker

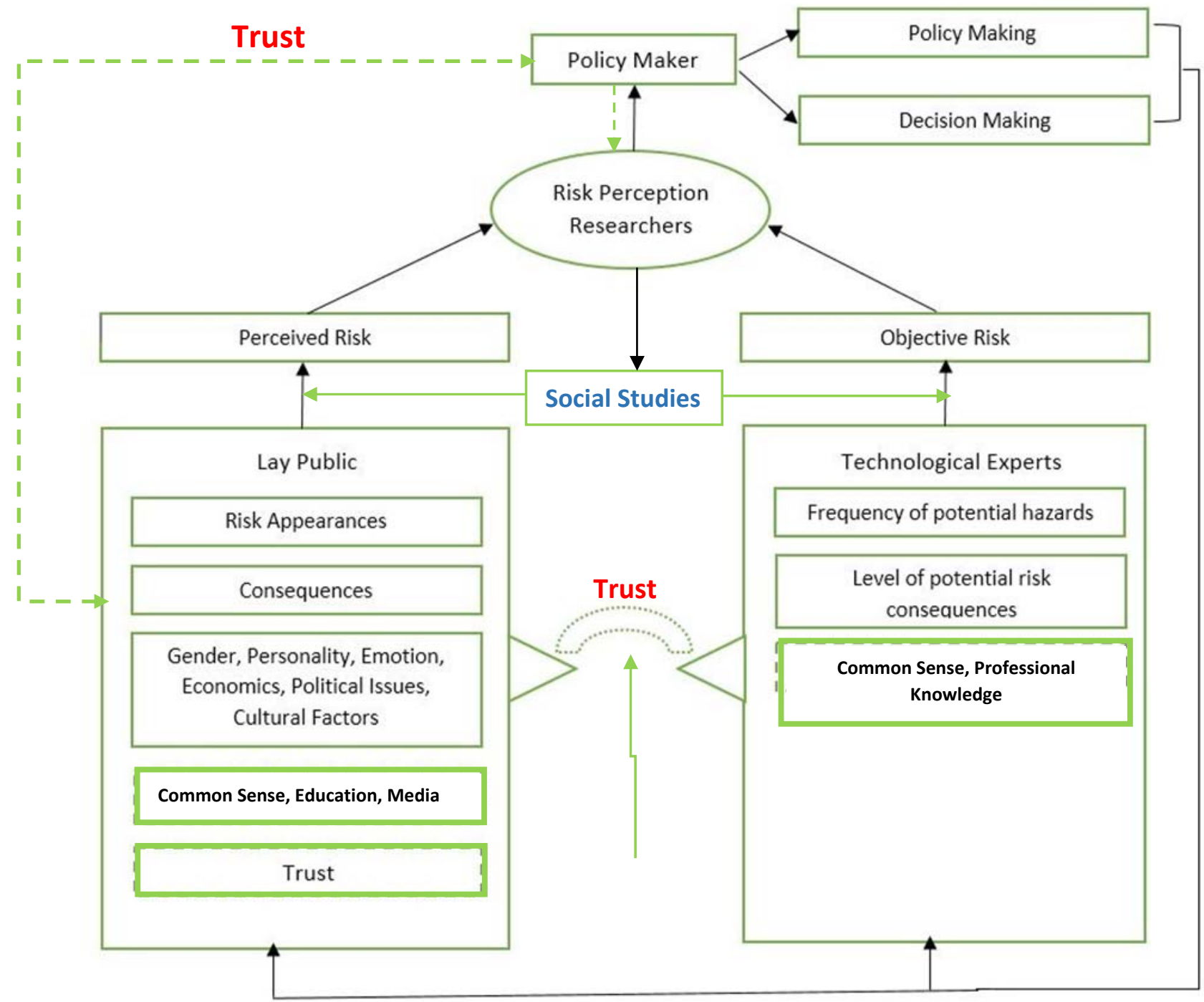

Fig. 1: Structure of major findings and process of risk perception studies. 
groups are rarely participating as one of the stakeholder groups for risk perception studies, which means the researchers may not really know how the policy makers are perceiving, technology risks and social risks. On the other hand, do policy makers really accept the results of risk perception studies, or how much agreement level do they have for the analysis results from lay public and the experts? A further step may need to make for closing the ring of social studies.

The risk perception from lay public and technological experts are different. The differences between perceived risks from lay public and technological experts triggered the risk perception study [51]. How the risk perception is different from stakeholder groups, and how is their ways of risk perception are different? Many research suggested that, the technological experts are perceiving the objective risks by probabilities of the hazardous events happening; while the lay public are perceiving the perceived risks as does it exists or not [14], [48]. In another word, the technological experts will perceive the risks by the frequency of potential hazards and level of potential risk consequences of the harmful things may happening, based on their professional knowledge and monitoring for the technology; the lay public are perceive the risks by consequences and risk appearances from the historical events, and would be affected by many other factors, which also makes the inconsistency on their risk perceptions [29]. These difference between the lay public and technological experts are not only hypothesizes that were tested through the studies, but also bring more attention on how to improve the risk communications between them. Nowadays, technologies are driving the development of modern society, innovative thinking is more and more encouraged for the technology and social management development, even from consumers' end. Researchers today are highly encouraging participations from all stakeholder groups for risk perceptions [14], which bring the attentions on the lay publics' risk perceptions again to the area. It is showing the trend that the researchers would need to build up a bridge to connect lay public and technological experts for a certain risk perception study so that the communication could be improved, and better solutions and innovations would be able to come out from the research.

Trust is the most important factor that cause the different risk perceptions, especially for the lay public. During the development of risk perception studies, affective factors that may have effects on perceptions of risks is an important area [5]. There are many factors that had been detected, especially for the lay public, which including: gender [18], [28], [36], race [28], cultural differences [21], [37], personality and emotions [18], [24], economics [18], knowledge [8], [14], [18], [48] and trust [8], [13], [21], [22], [24], [25], [34], etc. To the lay public, trust would become the most important factor of their risk perception, which also including the trust on their own perceptions, the trust on the media and society, the trust on policy makers and the trust on technological experts. The more they could trust, the less risk they will perceive. How to build the trust between lay public and technological experts, or lay public and policy maker, would need extra efforts. Some research were claiming that the reason why people perceive some technologies, especially for emerging technologies as very risky ones, is because they were taught that the technologies are dangerous [26]. That also raises another problem that how to make the public to trust the technology? Perhaps the mission for technological experts at this moment would not only be developing great technologies, but also convincing lay public to accept the technology, or even be enlightened from the perceived risks of the lay public. Also from a technology development perspective, the changes on the major technologies are not easily to be accepted by lay public at the very beginning, because the changes would cause extra switching costs. This switching costs would not only on the economics, but also on the psychological cognitions, feelings and behaviors, which may also lead to a different risk perception from the lay public. That's why new technologies need to work on "crossing the chasm" [49]. After crossing the chasm, a better way to maintain the trust from lay publics would probably try to make the technology better and better to meet their needs.

Knowledge impacts on risk perceptions. It is generally accepted that a person's knowledge about a topic impacts his or her risk perception and, in fact, delineates the lay public from technology experts. However, knowledge impacts depend on the type of knowledge and the context: For both of the lay public and technological experts, the common sense will not really affect the risk perception [48], since this is a similar foundation of knowledge for most of the people. Beyond that, lay public and technological experts would have different risk behaviors when they are facing the risk. To avoid risk or reduce risk, is based on how people are evaluating the risks. The same theory would also be applicable for risk perception researchers. Other than common sense, the more professional knowledge, the less risk would be perceived to an individual [14], [48]. That's also why technological experts are always having a lower risk perception than lay public on technologies. For risk perception researchers, when talking about the risk communication, even for lay public, a proper way which could help them to know more about the professional knowledge and principles of the technology, would also be helpful for reducing the risk perception [29]. Also, another way to inform the lay public on the technology is through the related policies, which could also potentially give the public a better understanding. For the risk perception researchers, would they really need the professional knowledge in order to do the risk perception study for a certain field, or industry, or technology? From Table 1, there is a sign, which was also suggested from the previous research, that risk perception researcher is not necessary to be in the professional field, or having any professional knowledge on the area [48]. The research frame work for risk perception studies would also be potential developed into a practical tool for technological 
management purposes: either protecting lay public from harmful things, or promote new opportunities and other potential risks to lay public. Both of the roles - protector and promotor [43], are also the role for the researchers to set the studies.

\section{Methodologies on Studying Risk Perception}

Methodologically, research on risk perception rests on pioneering research in cognitive and social psychology [39]. Table 2 provides an overview over commonly used methods: psychometric approaches and surveys use close-ended formats [5] and frequently analyze data with factor analysis, cluster analysis, correlation, scaling, risk rating, and regression. These methods are suitable for ranking of the importance of various risks as they are perceived by the public and correlation between risk rankings and other factors. Other methods are more inductive in nature and capture the concerns and risks as they becoming apparent through interaction with study participants in interviews, public hearings, posted comments on risk assessments, and workshops. The choice of method naturally depends on the objectives of the research: some methods are better suited for researching individuals while others are set up to capture data from groups. Also, some methods provide results in a way that is conducive to simulation and/or prediction. Other selection criteria are the time it takes to set-up the study and to analyze the data.

The commonly used methodologies are used to identify phenomena in risk perception and to test hypothesis that come out of this research. Most of the hypothesis testing is related to questions such “Does Factor X affect person's risk perception?" A few research provided some hypothesis like how the correlation between certain factors and different risk perceptions and how they will change when the factor is changing, and provide some strategic suggestions build up on the outcomes [14]. On the contrary, this also showing that different methodologies are focusing on different part of the risk perceptions from people. For their own focusing areas, they could serve the research goal and give the researchers useful outcomes. Certain kinds of methodologies, such as the public participation model [10], behavior analysis [9], or cognitive bias identification [15], the usage of them is to investigate the social psychological cognitions at certain period of time, instead of making a dynamic changing model. Also not all of the methodologies are focusing on serving the decision-making purposes.

There are also some common disadvantages of the methodologies mentioned from the studies, especially for the survey-based methods, which are widely used in the field of risk perception studies. The major drawbacks of survey-based methods that were talked about are: the representativeness of the samples, the limitation on the cognitive responses because of the questionnaire setups, the long time period of data collection, the emotional effects from the despondences may decrease the objectiveness of their answers, the one-way communication, and the inflexibilities of changing the process or questions around during the research. Other than these, from an overall evaluating, the existed methodologies for risk perception studies would mostly need a long time

TABLE 2: EVALUATION ON RISK PERCEPTION STUDY METHODOLOGIES

\begin{tabular}{|l|l|l|l|l|l|l|l|l|}
\hline \multicolumn{1}{|c|}{ Methodology } & $\begin{array}{l}\text { Usage } \\
\text { Researc } \\
\text { h Area }\end{array}$ & \multicolumn{1}{|c|}{$\begin{array}{c}\text { Data Collection } \\
\text { Level }\end{array}$} & \multicolumn{1}{|c|}{$\begin{array}{c}\text { Setup } \\
\text { Time }\end{array}$} & $\begin{array}{c}\text { Data } \\
\text { Collection } \\
\text { Time }\end{array}$ & $\begin{array}{c}\text { Analyzing } \\
\text { Turn-over } \\
\text { Time }\end{array}$ & $\begin{array}{c}\text { Simulation/ } \\
\text { Testing }\end{array}$ & $\begin{array}{l}\text { Planning/P } \\
\text { rediction }\end{array}$ & $\begin{array}{l}\text { Flexibility } \\
\text { of Process }\end{array}$ \\
\hline $\begin{array}{l}\text { Psychometric Paradigm } \\
\text { [8], [14], [27], [30], [39] }\end{array}$ & Psy* & Individual/Group & Medium & Long & Long & No & Yes \\
\hline $\begin{array}{l}\text { Survey/Questionnaire } \\
\text { [14], [19], [20], [31], } \\
\text { [46] }\end{array}$ & $\begin{array}{l}\text { Socio*, } \\
\text { Psy, } \\
\text { Buz* }\end{array}$ & Individual & Short & Long & Long & Depends & Depends & No \\
\hline $\begin{array}{l}\text { Interview [22], [32] } \\
\text { Psy, } \\
\text { Buz }\end{array}$ & Individual/Group & Medium & Long & Long & No & No \\
\hline $\begin{array}{l}\text { Literature Review [26], } \\
\text { [42], [45], [47] }\end{array}$ & All & All & Long & Long & Short & No & No & No \\
\hline Case Study [8], [11] & All & All & Long & Long & Medium & Yes & Depends & No \\
\hline $\begin{array}{l}\text { Socio-Cultural Theory } \\
\text { [20] }\end{array}$ & Socio & Group & Long & Long & Medium & No & No & No \\
\hline Mental Model [27] & Psy & Individual/Group & Long & Long & Medium & Yes & Depends & Depends \\
\hline $\begin{array}{l}\text { Structured Weighting } \\
\text { Model (Benefits vs. } \\
\text { Risks) [43], [46] }\end{array}$ & $\begin{array}{l}\text { Socio, } \\
\text { Psy }\end{array}$ & Individual & Short & Medium & Short & No & No & No \\
\hline $\begin{array}{l}\text { Public Participation } \\
\text { Model [10] }\end{array}$ & Socio & Group & Medium & Long & Medium & No & No & No \\
\hline $\begin{array}{l}\text { Technology Acceptance } \\
\text { Model [34] }\end{array}$ & Tech* & Group & Medium & Medium & Medium & Yes & No & No \\
\hline $\begin{array}{l}\text { Behavior Analysis [9] } \\
\text { Pognitive Bias } \\
\text { Identification [15] }\end{array}$ & Psy & Individual & Medium & Long & Long & Depends & No & No \\
\hline
\end{tabular}

*Keys: Psy = Psychology; Socio $=$ Sociology, Buz = Business, Tech $=$ Technology 
period of preparing, data collection, and analysis, which may not effective enough to serve today's needs. Furthermore, some new functions are also in need on the methodology development, such as being able to do scenario simulations, predictions, and dynamically flexible.

To be conclude from the literature review, studying risk perceptions from multiple stakeholder groups is important for technology management. Understanding the different risk perceptions is helpful for improving the strategical decisionmaking process for technology managers; and also would be benefit for policy makers on developing more effective policies. There are different perspective and receptions from different stakeholder groups, but current research methods are still having limitations on building up a risk communication including all the stakeholder groups into the conversation. A need of a better practical tool for risk perception studies is a gap from the previous studies.

\section{FUZZY COGNITIVE MAPS (FCM) AND RISK PERCEPTION}

A. Requirements for novel approaches to capturing stakeholder risk perception for technology management

The literature review above identifies the major affective factors in risk perception for different stakeholder groups, including: risk appearance, consequences, gender, personality, emotions, economics, political issues, cultural factors, knowledge, trust, frequency of potential hazards, and level of potential risk consequences. All of these factors would affect different stakeholder groups' risk perception, but for each stakeholder group, they may not know the major perceived risks and important factors from another group. In the recent years, technological experts and social managers would like to know more and more from lay publics on how they are perceiving the technological risks. On the other hand, if lay public could understanding more on how the technological experts and policy makers are considering about the technological risks, can help lay public with understanding the technology better. The technological experts could provide their point of view on the technology based on their professional knowledge. The policy makers could give lay public more confidence and trust from the policy-making perspective, which would also help lay public on building trust to technological experts. Meanwhile, policy makers will know clearly on what policy should they making for lay public's general interests. From a management perspective, the circle of management should be closed by connecting all the possible stakeholder groups into the ring. To get information from multiple perspectives is also the development trend of management field. Combining opinions from both insiders and outsiders could give technology managers clear ideas on where to lead the development strategy. In order to achieve the connections with all the stakeholder groups that involves into the risk perception studies, a better practical tool need to be developed for getting all the parties into the risk communication. Fuzzy Cognitive Maps (FCM) could provide the function to capturing all stakeholder groups' risk perceptions equally, directly and dynamically. By comparing the different maps from different stakeholder groups, a better way of risk communication could also be built.

TABLE 3: EVALUATION ON RISK PERCEPTION RESEARCH METHODOLOGIES WITH FUZZY COGNITIVE MAPS

\begin{tabular}{|l|l|l|l|l|l|l|l|l|}
\hline \multicolumn{1}{|c|}{ Methodology } & $\begin{array}{c}\text { Usage } \\
\text { Research } \\
\text { Area }\end{array}$ & Data Collection Level & \multicolumn{1}{|c|}{$\begin{array}{c}\text { Setup } \\
\text { Time }\end{array}$} & $\begin{array}{c}\text { Data } \\
\text { Collection } \\
\text { Time }\end{array}$ & $\begin{array}{c}\text { Analyzing Turn- } \\
\text { over Time }\end{array}$ & $\begin{array}{c}\text { Simulation/T } \\
\text { esting }\end{array}$ & $\begin{array}{c}\text { Planning/Pr } \\
\text { ediction }\end{array}$ & $\begin{array}{c}\text { Flexibility of } \\
\text { Process }\end{array}$ \\
\hline $\begin{array}{l}\text { Psychometric Paradigm } \\
\text { [8], [14], [27], [39] }\end{array}$ & Psy* & Individual/Group & Medium & Long & Long & No & Yes \\
\hline $\begin{array}{l}\text { Survey/Questionnaire } \\
{[11,13,19,27,28,50]}\end{array}$ & $\begin{array}{l}\text { Socio*, } \\
\text { Psy, Buz* }\end{array}$ & Individual & Short & Long & Long & Depends & Depends & No \\
\hline Interview [22], [32] & $\begin{array}{l}\text { Socio, Psy } \\
\text { Buz }\end{array}$ & Individual/Group & Medium & Long & Long & No & No \\
\hline $\begin{array}{l}\text { Literature Review [26], } \\
\text { [42], [45], [47] }\end{array}$ & All & All & Long & Long & Short & No & No & No \\
\hline Case Study [8], [11] & All & All & Long & Long & Medium & Yes & Depends & No \\
\hline $\begin{array}{l}\text { Socio-Cultural Theory } \\
\text { [20] }\end{array}$ & Socio & Group & Long & Long & Medium & No & No & No \\
\hline Mental Model [27] & Psy & Individual/Group & Long & Long & Medium & Yes & Depends & Depends \\
\hline $\begin{array}{l}\text { Structured Weighting } \\
\text { Model (Benefits vs. } \\
\text { Risks) [43], [46] }\end{array}$ & Socio Psy & Individual & Short & Medium & Short & No & No \\
\hline $\begin{array}{l}\text { Public Participation } \\
\text { Model [10] }\end{array}$ & Socio & Group & Medium & Long & Medium & No & No \\
\hline $\begin{array}{l}\text { Technology Acceptation } \\
\text { Model [34] }\end{array}$ & Tech* & Group & Medium & Medium & Medium & Yes & No \\
\hline Behavior Analysis [9] & Socio, Psy & Individual & Medium & Long & Long & Depends & No & No \\
\hline $\begin{array}{l}\text { Cognitive Bias } \\
\text { Identification [15] }\end{array}$ & Psy & Individual/Group & Medium & Medium & Long & No & No & No \\
\hline $\begin{array}{l}\text { Fuzzy Cognitive Maps } \\
\text { (FCM) }\end{array}$ & $\begin{array}{l}\text { Socio, } \\
\text { Psy, Buz }\end{array}$ & Individual/Group & Medium & Short & Medium & Yes & Yes & Yes \\
\hline
\end{tabular}

*Keys: Psy = Psychology; Socio $=$ Sociology, Buz = Business, Tech $=$ Technology 
New researchers in the field are suggesting to look for new tools other than survey-based methodologies, which could possibly fill the gap of the disadvantages for existing methodologies, and also could be easily adopted, quickly identify the risk perceptions, and could simulating some decision-making scenarios. They would like to find a tool that could serve the strategic planning and decision-making purposes better than before [14]. For this kind of purpose, Fuzzy Cognitive Maps (FCM) could possibly be a method for investigating differences in risk perception among stakeholders and stakeholder groups. Building up on the previous table (Table 2), Fuzzy Cognitive Maps could be a way to functional and theoretically serve the new needs for risk perception studies (as in the following Table 3 ).

From Table 3, Fuzzy Cognitive Maps (FCM) has a widely usage on data collection level, which could be used both for individual and groups. The data collection time is relatively short for the study, which may as short as a workshop with stakeholders. Fuzzy Cognitive Maps could also provide simulations predictions and flexibilities on analyzing process, which could serve the new needs of risk research.

\section{B. A Brief Introduction on Fuzzy Cognitive Maps (FCM)}

As it is talked above, knowledge and trust are two important factors that would affect person's risk perception. For this reason, risk perception studies could also be benefit from models based on people's knowledge, and their feelings of component connections and even trust feelings. Fuzzy cognitive maps, which is basis on cognitive mapping provide a means to do this. Özesmi et al. [50] developed a multi-step fuzzy cognitive mapping approach for analyzing how people perceive an ecosystem, and for comparing and contrasting the perceptions of different people or groups of stakeholders. The multi-step approach is a synthesis of relevant useful techniques form may disparate disciplines on cognitive mapping [50].

"A cognitive map can be described as a qualitative model of how a given system operates. The map is based on defined variables and the causal relationships between these variables. These variables can be physical quantities that can be measured such as amount of precipitation or percent vegetation cover, or complex aggregate and abstract ideas, such as political forces or aesthetics. The person making the cognitive map decides what the important variables are which affect a system and then draws causal relationships among these variables indicating the relative strength of the relationships with a number between -1 and 1 . The directions of the causal relationships are indicated with arrowheads. Cognitive maps are especially applicable and useful tools for modeling complex relationships among variables. With cognitive mapping the decision-makers; maps can be examined, compared as to their similarities and differences, and discussed. In addition the effects of different policy options can be easily modeled." - Özesmi, 2004 [50]
From descriptions on what is a fuzzy cognitive map, it could directly map out person's cognitions on a certain subject. The maps could be different, and could be examined, compared, or combined. Different perceptions could be modeled easily, together with different policy options. All of these characters and natures of FCM could serve the purpose of risk perception analysis, and provide valuable decisionmaking evidence to the related stakeholders. By building up the maps and study them, the risk communication could also be potentially improved among different stakeholders.

The regular approach of FCM would including following steps: drawing the cognitive maps; coding the cognitive maps into adjacency matrixes; analyzing the structure; similarities and differences of stakeholders or stakeholder groups; analyzing the outcomes of cognitive maps using neural network computation; and simulating different options or scenarios [50]. Basis on the approaches, the risk perception studies could also be designed into this way. In the following is a case study on wildfire risk perception, using FCM as a major research tool, to investigate the risk perceptions on wildfire from 14 college students, which could be considered as the group of lay public group as fit into this research.

Considering to adopt FCM as a tool capture risk perceptions from different stakeholder groups in the content of technology management, the approach would be as the following:

- Preparing initial components, which could come from the existing research in the field, identify the important components from literature review or from field experts. These initial components could become the start point of the map building.

- Building up the visual map from stakeholders/stakeholder groups. The way to build up the visual map of Fuzzy Cognitive Maps, which would also be shown in the following session of paper, is to let the stakeholders make connections between different components, and put the possible impact from one component to another, make all the dots into a network map. Stakeholders could also come up with their own components that they are thinking that would be relevant to the topic, or from their own perceptions.

- Creating Adjacency Matrix. The adjacency matrix shows the impact weights that on every connection between each two of the components in the visual map. With adjacency matrix, simulations and predictions could be tested through squashing functions.

- Structural Analysis on the visual map. This analysis would majorly look into the connection structure of the network of the map. In that way, different kinds of components could be able to identified, which may deliver different efforts with the scenario testing. The major kinds would include: central concepts, driver concepts, and original concepts.

- Scenario testing. According to the structure of the map, there would be several factors that would connected to the potential decision-making process. From the management 
perspective, pick up relevant factors and set their beginning points at either increasing the weight, decrease the weight, keep it stable, or inactive. Then through the calculations of squashing functions, the scenario testing could be run based on the pre-setups on components.

- Analyzing on conclusions and management suggestions. By looking into the different scenarios, relevant management suggestions could be made, by taking actions on certain factors from the assumption for scenarios.

C. Illustration: Studying Risk Perceptions with FCM - the example of wildfire Risks

This case study was using the data collected from engineering students. Since they are technology experts in their engineering field, engineering and technology risk perceptions may not be able to show the different cognitive patterns of experts and lay people. Using wildfire risks as an example to them, would then make them becoming "lay public" in the field, and give the impression of how FCM works for generating risk perceptions from different stakeholder groups. And then the process could be also adopted into technology management field.

From a literature review on wildfire risk management, the experts were also looking for some kinds of methods or tools that could be helpful for the risk assessment of wild fire and improve the managerial decision-makings. More data-based methods had also been adopted into the area, such as using probabilistic modeling on analyzing different risks for wildfire risk assessment [51] using data in certain area to test the synthetic scenario results in a "decision space" of wildfire [52] or leveraging the appropriate decision support tools which can facilitate wildfire risk assessment and improve decision-making [53], etc. This case study presented is belonging to a whole set of research project on wildfire risks, which could be helpful for the policy makers to make judgements about risk management policies for wildfire. Here in the following figure (Figure 2) is showing the whole research approach of the research, which also enlightened the role of FCM playing in the whole project.

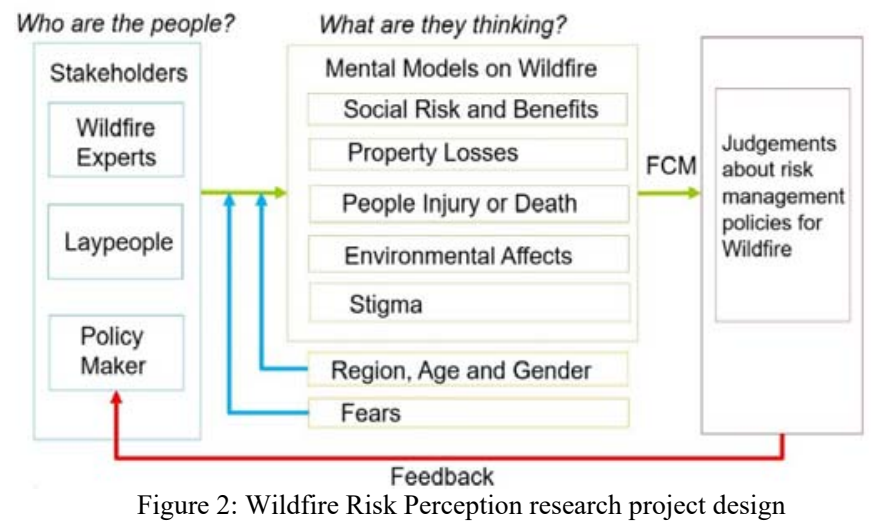

From the figure above, all of the three major stakeholder groups will be involved into the research as the research subjects and provide their risk perceptions on wildfire risks. Fuzzy Cognitive Maps could be helpful on capturing their different cognition models for the analysis, and come up with management suggestions. The case study could be insert into one part of detecting the perceived risks from lay people.

\section{Step 1: Preparing the start components}

This is the first step to begin the map building for students. After a literature review and some initial talks with wildfire experts, start components for students to start with had been listed as showing below ${ }^{1}$ :
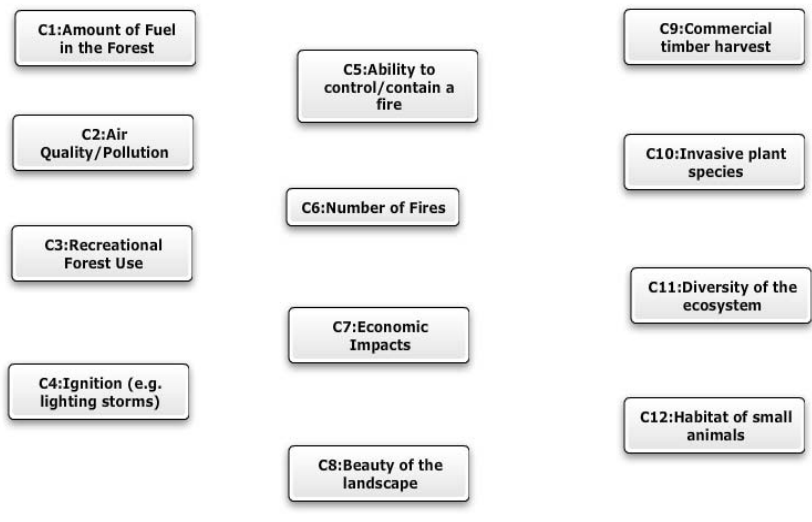

\footnotetext{
${ }^{1}$ The online FCM tool showing in the paper is from www.mentalmodeler.com .
} 


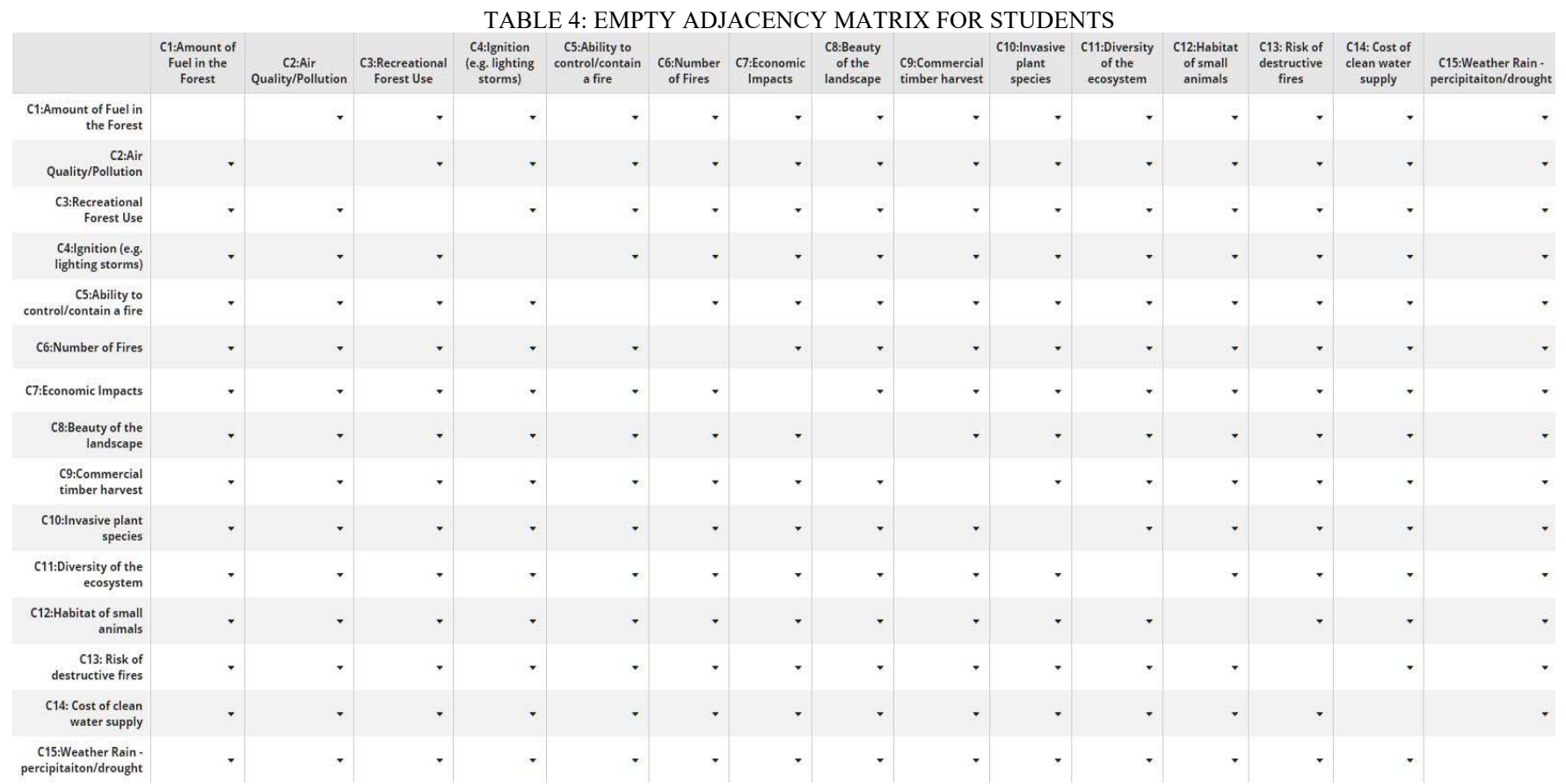

And also an empty adjacency matrix was also ready for students to fill in the number between -1 to 1 as showing in the table (Table 4).

From the figure above, there are 15 components which are ready for students to make connections on with them. The research objective is "C13: Risk of Destructive Fires", the regular beginning components are: "C1: Amount of Fuel in the Forest", "C2: Air Quality/Pollution", “C3: Recreational Forest Use", "C4: Ignition (e.g. lighting storms)", "C5: Ability to control/contain a fire", "C6: Number of fires", "C7: Economic Impacts", "C8: Beauty of the Landscape", "C9: Commercial Timber Harvest", "C10: Invasive Plant Species", "C11: Diversity of the Ecosystem" and "C12: Habitat of Small Animals". There are also two add-on components that the students could connect them into the model or not, which are "C14: Cost of Clean Water Supply", and "C15: Weather Rain - Precipitation/drought". Also if the students could come up with more other factors that they feel like should be put into the model, they could also add in other relevant factors. The purpose of doing this case study is aiming to get the opinions on how the students' perception on which factors would affect the risk of destructive fires. They would give the connections between components, and the degree of causal connections among the components. The adjacency matrix will reflect their connections and numbers of the degrees of the map once they finished the connections. In order to simplify the process for students and not affect the final map, the students would only need to choose $-1,0$, and 1 as the degree of causal connections in their maps.

\section{Step 2: Collect the Individual Maps}

After each of the students who were involved into this case study had gave all of the connections among the components, their individual maps should be collected by the research team. For a regular FCM study process, the collected maps would be used for map comparison for differences, or map integration for similarities. As one type of stakeholder groups as a whole, their maps would be used for finding the similarities and potentially integrate together, to build up a final map that could represent the perceptions for most peoples' interests within this group.

One example of a student's FCM is showing as figure 4 and his adjacency matrix is showing as in Table 5.

From the map and the table, this student did not connect the add-on components with any of other components, which is acceptable from the research design.

\section{Step 3: Creating the Group Map}

As mentioned before in the paper, the following step for the collected individual maps would need to be combined together for a group map. In this way, the map could be able to reflect the general interests, judgements and perceptions from the whole group. That would representing the group members' opinions as a whole. After calculating the average causal degree between each two components, a group map could be showed as figure 5 . 


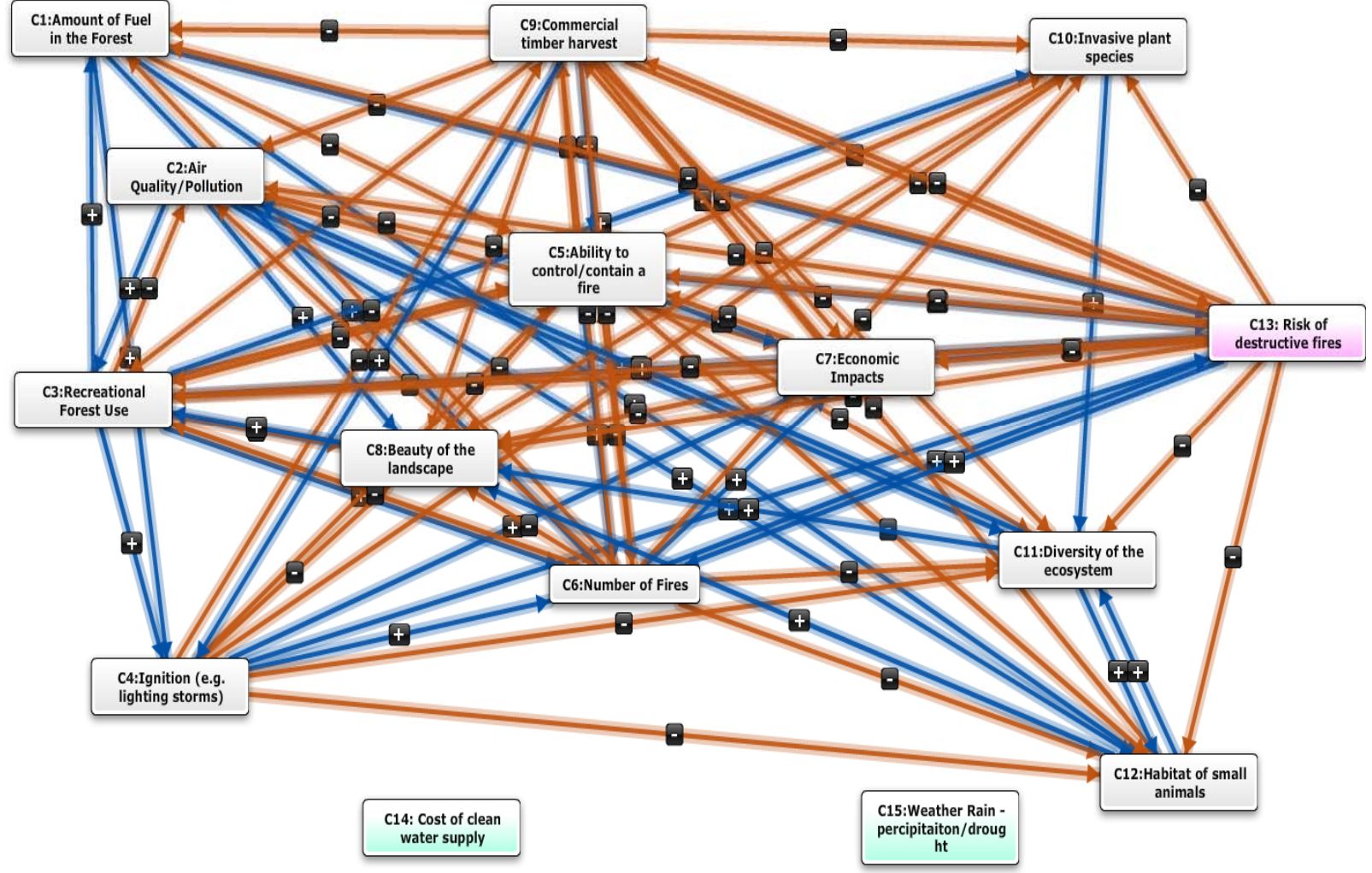

Figure 4: An example of Wildfire Risk FCM from the case study

TABLE 5: THE ADJACENCY MATRIX FROM THE EXAMPLE FCM

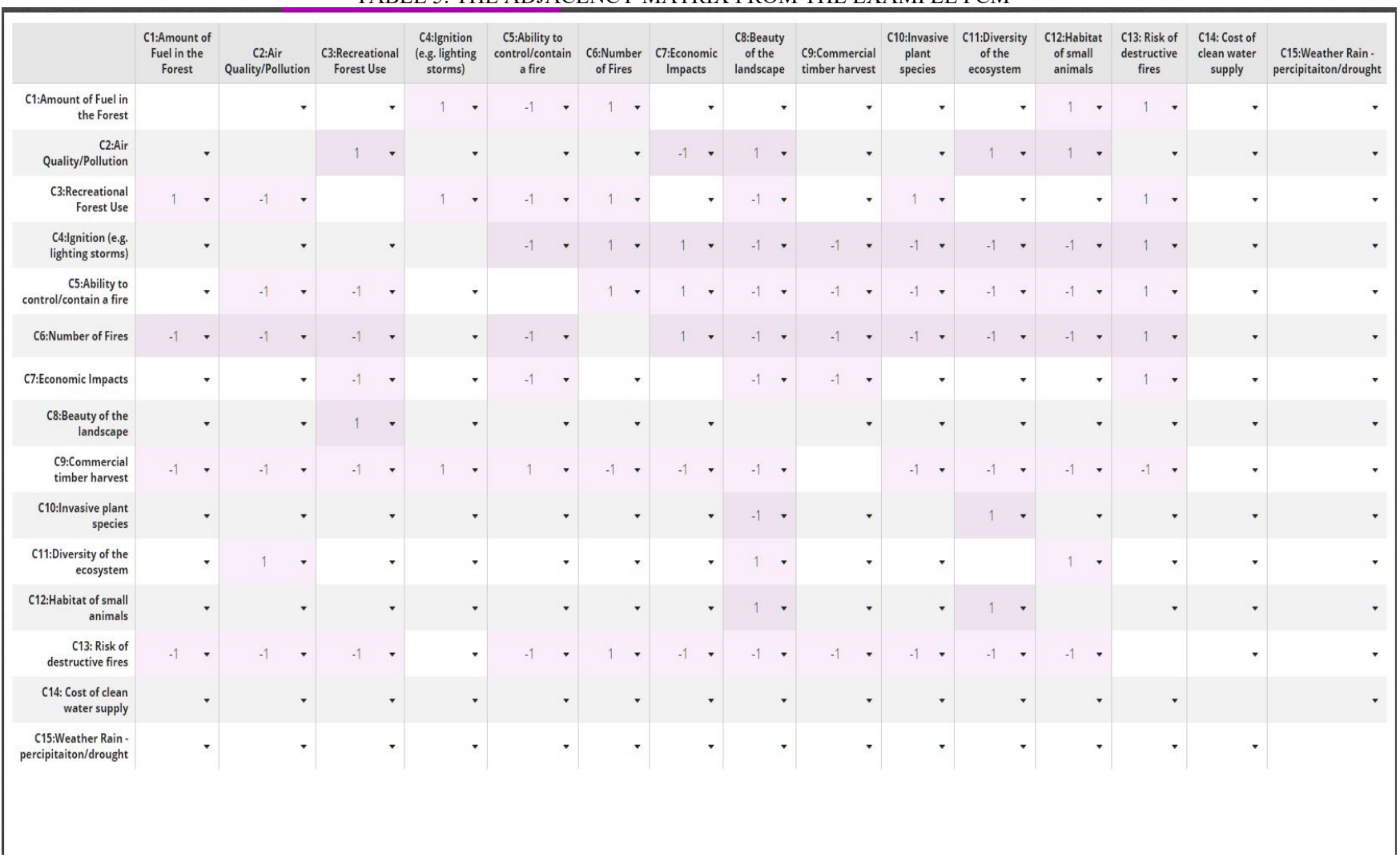




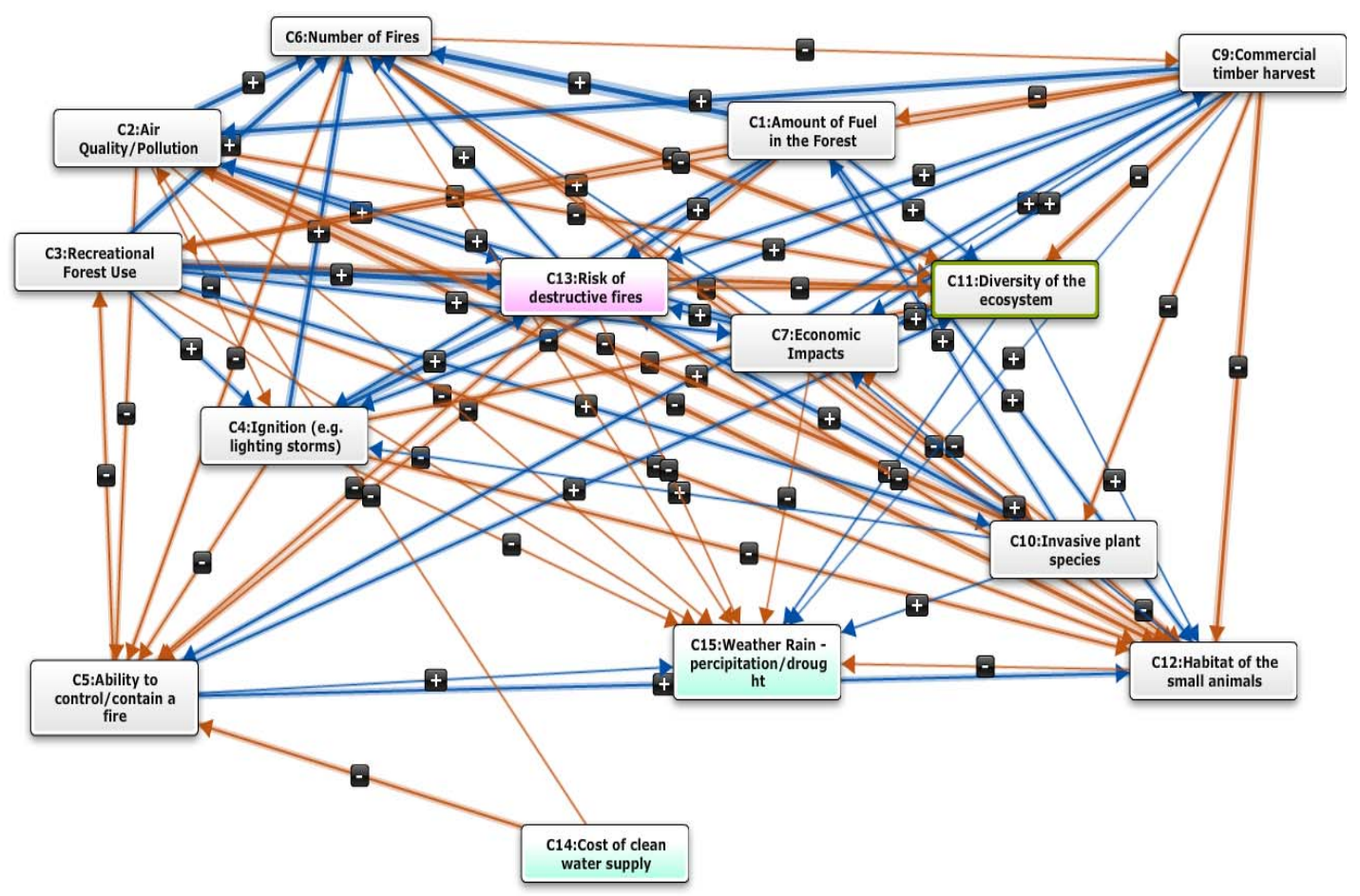

Figure 5: A Group FCM for Wildfire Risk Case Study

Seeing through the map, the different of thickness of the arrow lines represented an average agreement of causal numbers for each connection from the team, which could be possibly reflect the most peoples' interests on the perception.
It seems like the students did not really add in other components other than the given ones.

The adjacency matrix is showing as the following:

TABLE 6: THE ADJACENCY MATRIX FROM THE GROUP MAP

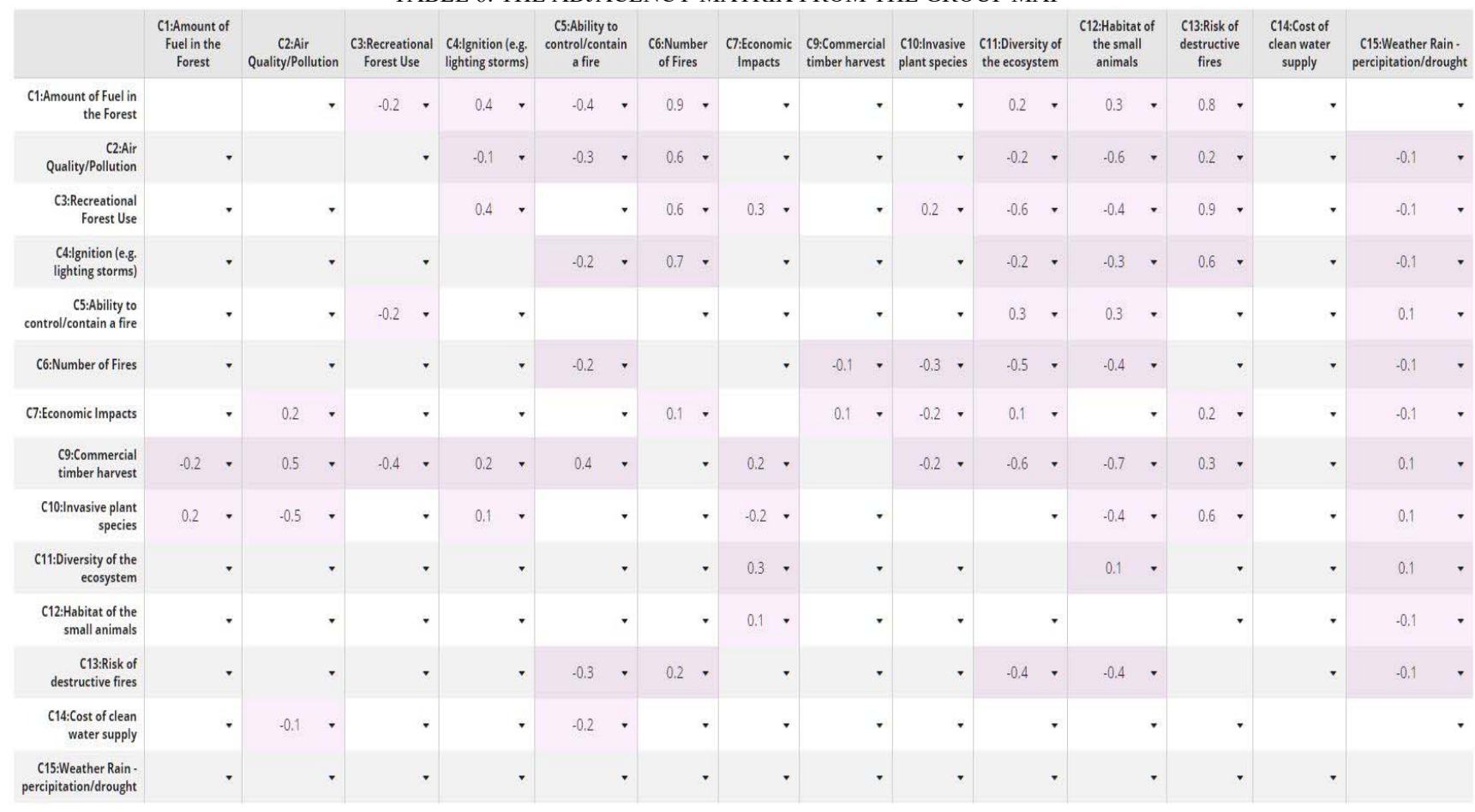


TABLE 7: THE STRUCTURAL ANALYSIS OF THE WILDFIRE RISK GROUP PERCEPTION MAP

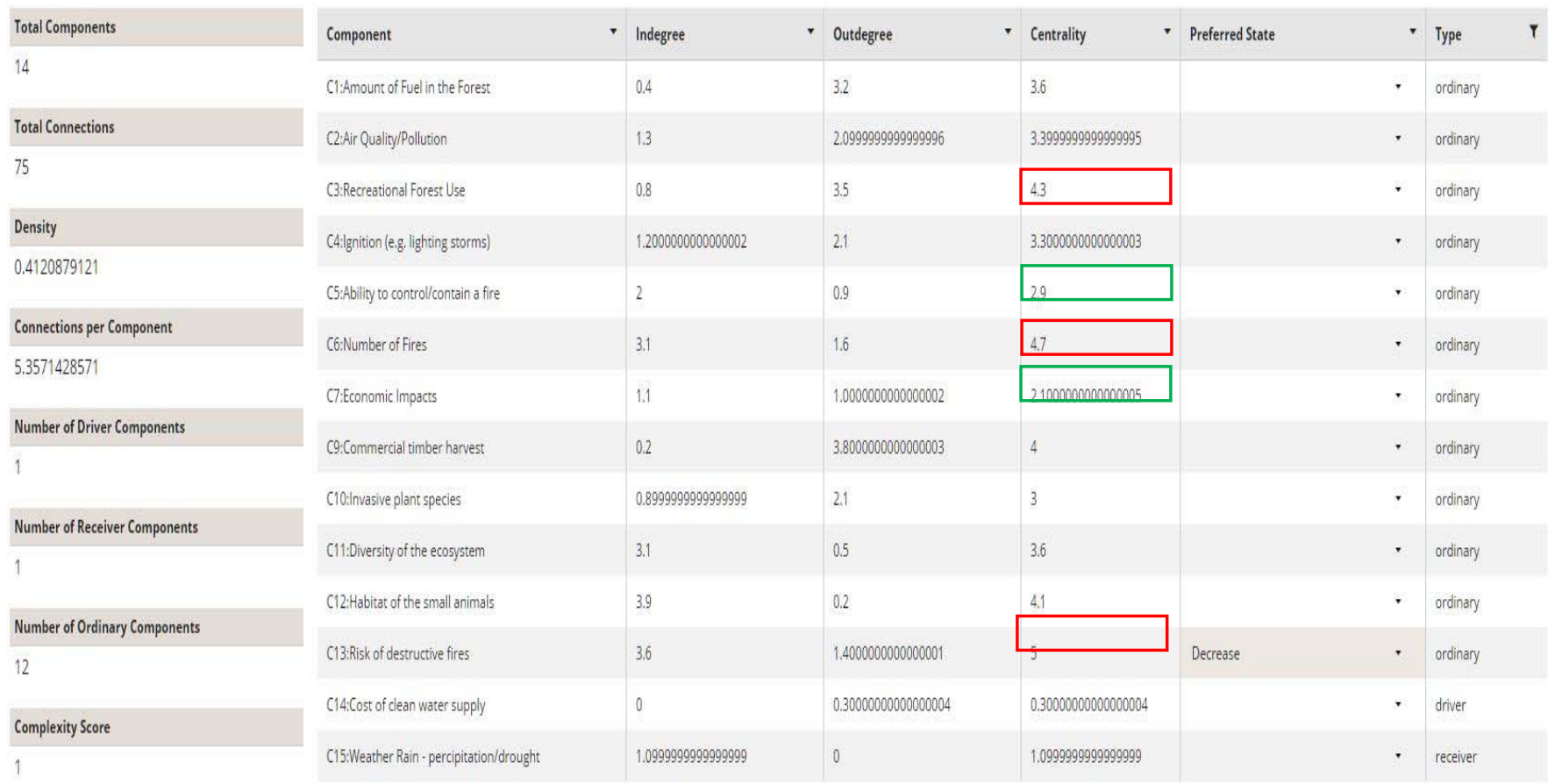

The adjacency matrix reflected the structure of the map, on how it is connected with the components. These information would be able to allow the researchers to do some analysis and running scenario tests through the map.

\section{Step 4: Structural Analysis of the Group Map}

The structural analysis of the group map is showing as the table 7.

According to the structural analysis of the wildfire risk group perception map, the centrality value is showing out which components got the most connections and least connections in the map.

The research objective, which is the "C13: Risk of destructive fires" has the most connections $($ Centrality $=5$ ) from the other components, which means almost every component has direct or indirect connections with it. Other than this, within the regular given components, another two most important components that students were perceived as the major factors to the fire risk are "C6: Number of Fires" (Centrality $=4.7$ ) and "C3: Recreational Forest Use" $($ Centrality $=4.3)$. This is showing a strong signal that for lay people, without any professional knowledge in the field, most of their risk perceptions would mostly related to their common sense. In this case, the common sense is that, more fire risk means more numbers of fires, while how to use the forest is also important for controlling the risks. On the other hand, "C5: Ability to control/contain a fire" $($ Centrality $=2.9)$ and "C7: Economic Impacts" (Centrality $=2.1)$ became the least important components through their perceptions. That's also related to their common senses like the ability to control/contain a fire may not be really helpful for reducing the wildfire risk, while also not increase it, because the wildfire are mostly started by natural, and it is an objective risk. The economic impacts may out of the picture because of this could be considered as a long-reach component that is not closely relevant to the wildfire risks.

\section{Step 5: Scenario Running}

Another powerful function of Fuzzy Cognitive Maps is scenario running, which could be helpful on decision-making simulations. Since the structure of the map had been set, by making changes on one or more components, the related changes on other factors, which are basis on the cognitions from this group of people, would be shown out as a simulation of possible choices on decision-making.

From the previous steps, the group FCM had been built up, which could also functionally for scenario running. Several possible scenarios and the outcomes could be shown as the following; in order the changes and impact clearly, the changes to the components will be made with a degree of either 1 , or -1 . And other than the listed scenarios below for the case study, any scenarios basis on making changes of components in the map could be made with any combination of changes. 
Scenario I. Reducing the amount of fuel in the forest.

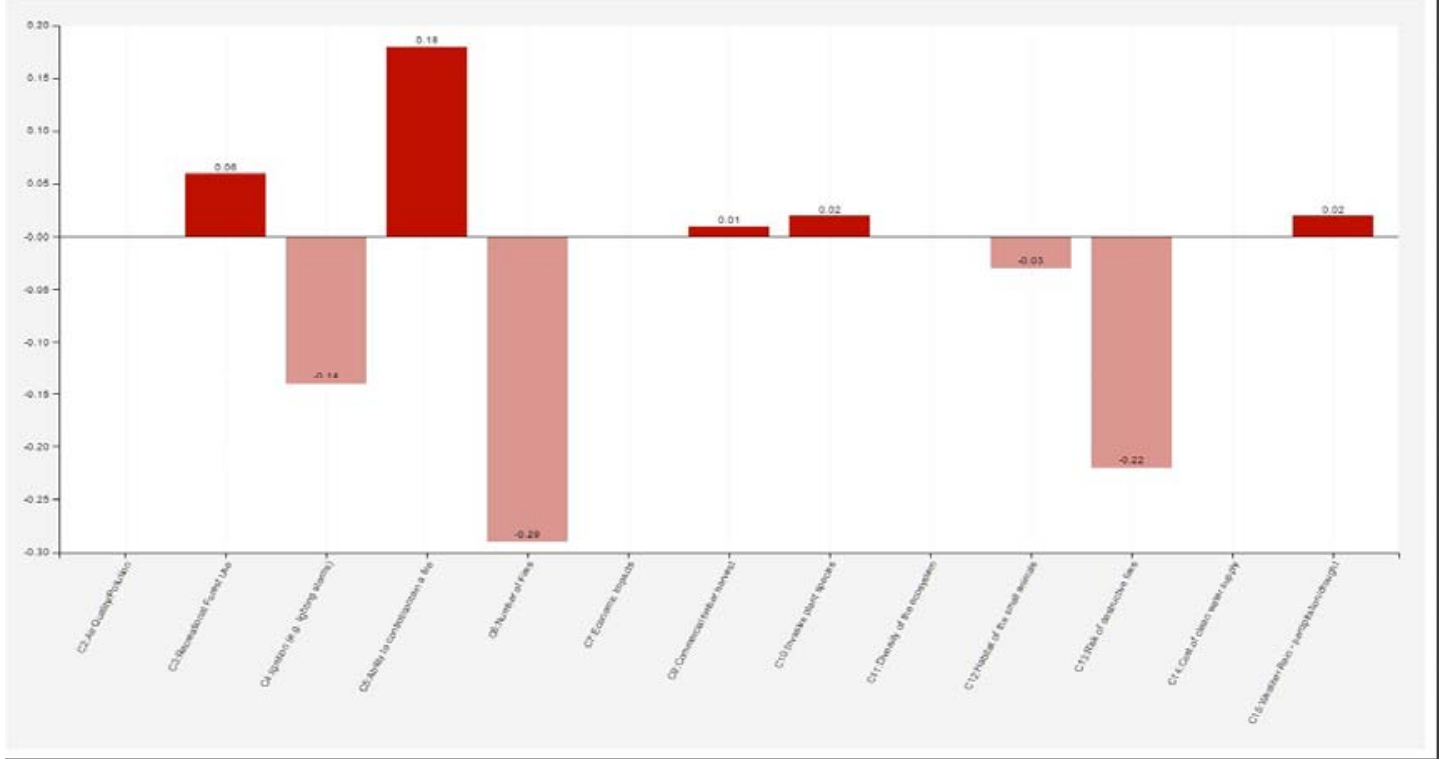

Figure 6: Scenario I Result

Scenario II. Increasing the recreational forest use.

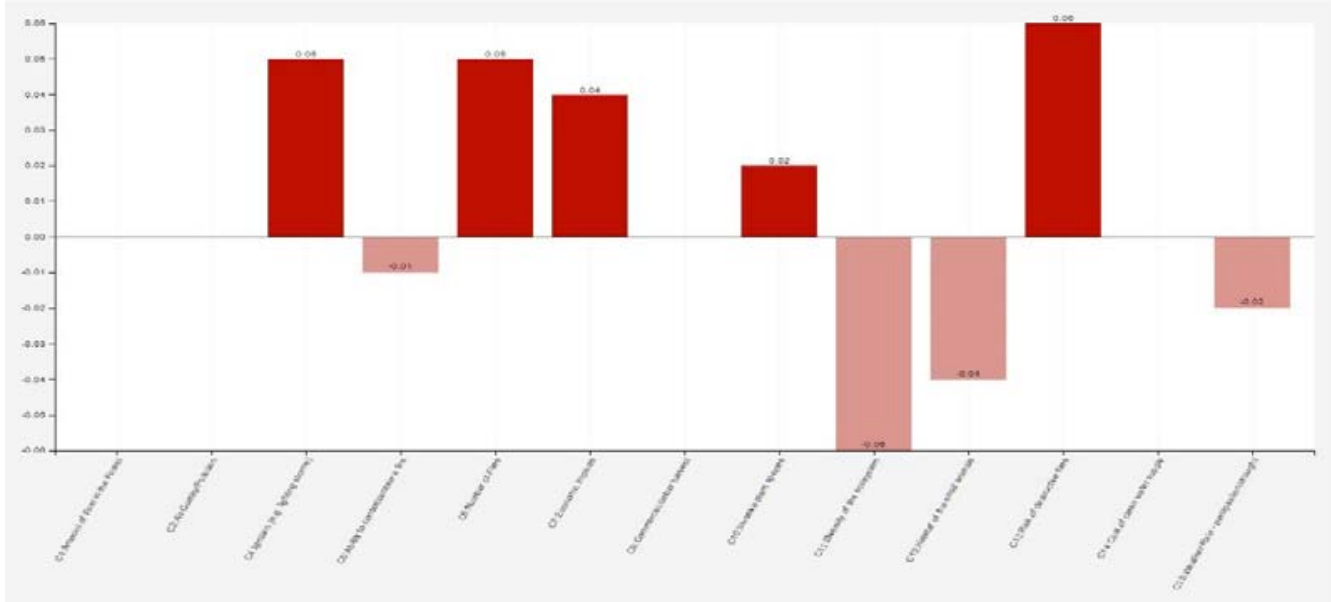

Figure 7: Scenario II Result

Scenario III. Increasing ability of control/contain a fire.

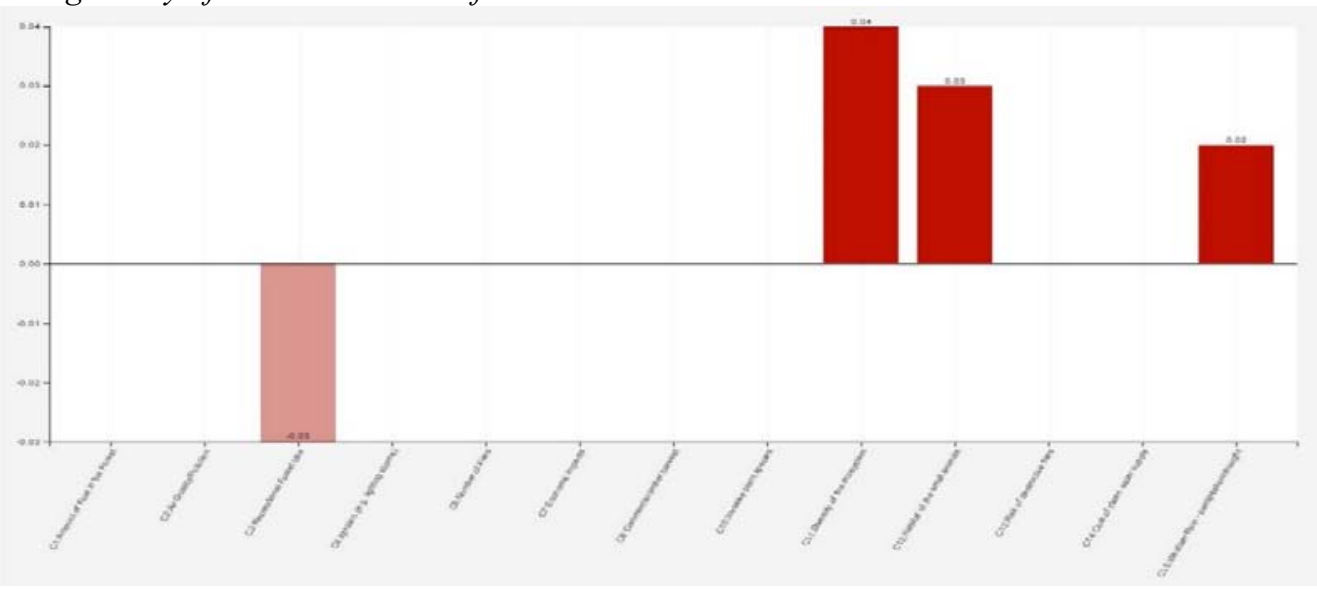

Figure 8: Scenario V Result 
Scenario IV. Increasing commercial timber harvest.

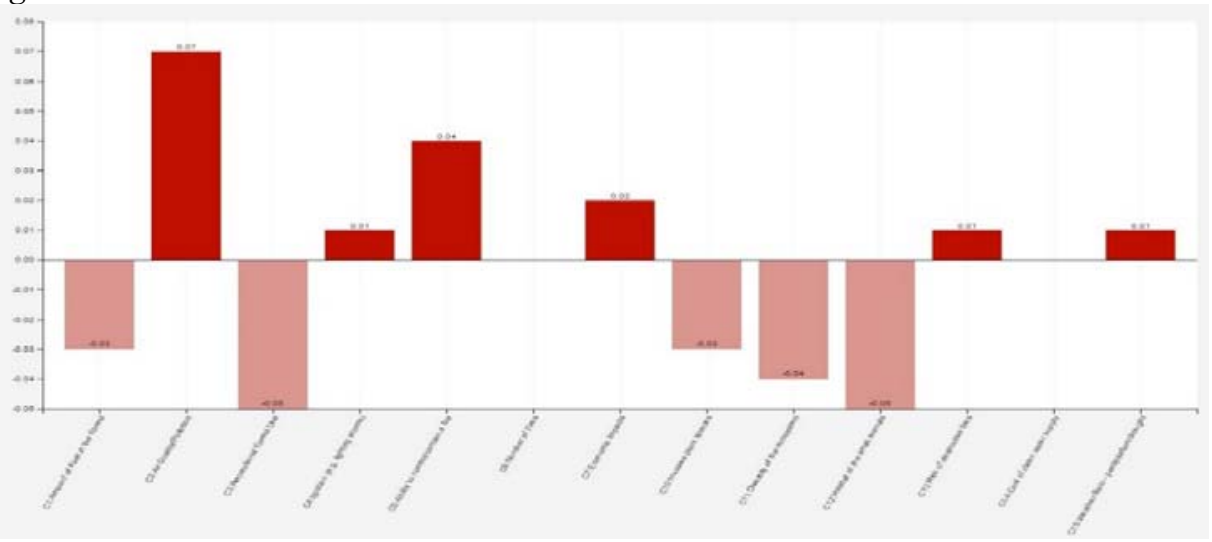

Figure 9: Scenario IV Result

Scenario $V$. Reducing the fuel amount, increasing recreational forest use and fire control abilities.

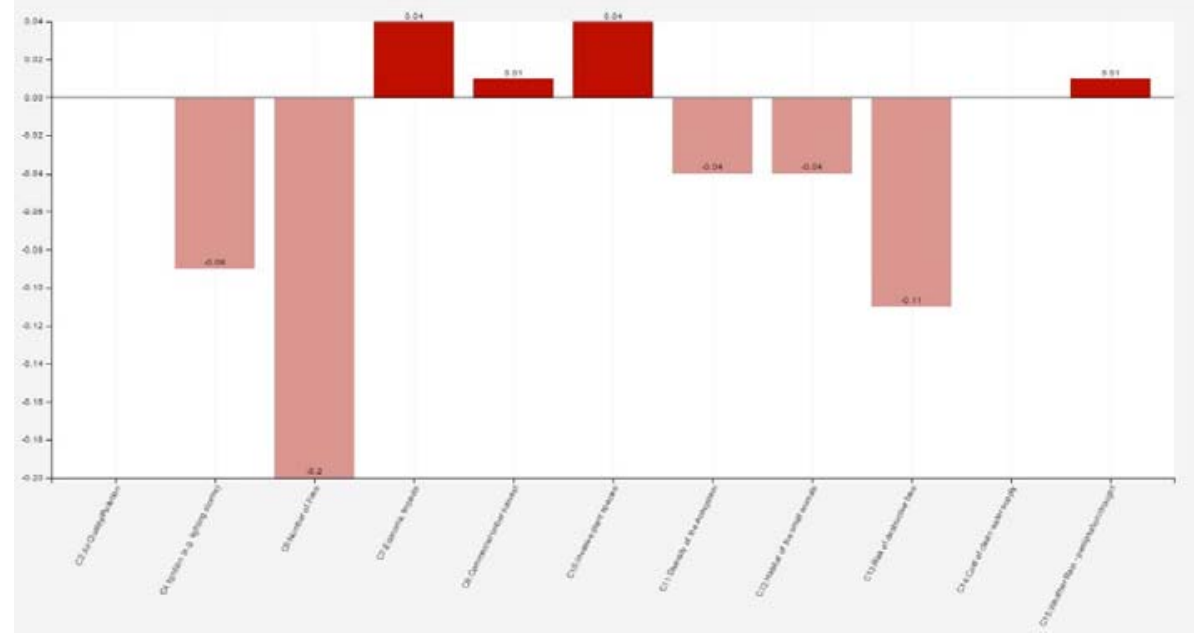

Figure 10: Scenario V Result.

Scenario VI. Increasing fire control abilities and commercial timber harvest, reducing the cost of clean water supply.

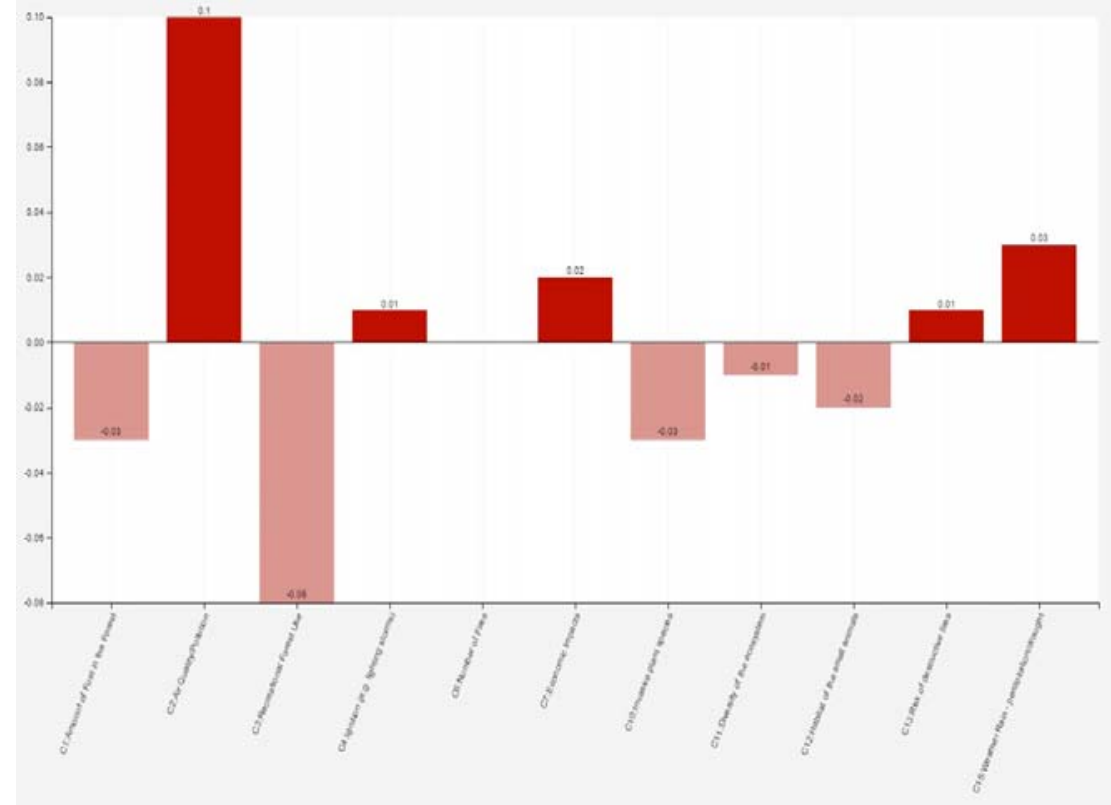

Figure 11: Scenario VI Result 
2016 Proceedings of PICMET '16: Technology Management for Social Innovation

\begin{tabular}{|c|c|c|c|c|c|c|c|c|}
\hline Changes on Components & $\begin{array}{l}\text { C1: } \\
\text { Fuel } \\
\text { Amount }\end{array}$ & $\begin{array}{l}\text { C3: } \\
\text { Recreational } \\
\text { Forest Use }\end{array}$ & $\begin{array}{l}\text { C5: Fire } \\
\text { Control } \\
\text { Ability }\end{array}$ & $\begin{array}{l}\text { C6: } \\
\text { No. of } \\
\text { Fire }\end{array}$ & $\begin{array}{l}\text { C7: } \\
\text { Economic } \\
\text { Impacts }\end{array}$ & $\begin{array}{l}\text { C12: Habitat } \\
\text { of Small } \\
\text { Animals }\end{array}$ & $\begin{array}{l}\text { C13: Risk of } \\
\text { Destructive } \\
\text { Fire }\end{array}$ & $\begin{array}{l}\text { C15: } \\
\text { Weather } \\
\text { Rain }\end{array}$ \\
\hline $\begin{array}{l}\text { Scenario I: Decreasing Fuel } \\
\text { Number }\end{array}$ & N/A & -0.14 & 0.18 & -0.29 & N/A & -0.03 & -0.22 & 0.02 \\
\hline $\begin{array}{l}\text { Scenario II: Increasing } \\
\text { Recreational Forest use }\end{array}$ & $\mathrm{N} / \mathrm{A}$ & $\mathrm{N} / \mathrm{A}$ & -0.01 & 0.05 & 0.04 & -0.04 & 0.06 & -0.02 \\
\hline $\begin{array}{l}\text { Scenario III: Increasing Fire } \\
\text { Control Ability }\end{array}$ & $\mathrm{N} / \mathrm{A}$ & -0.03 & $\mathrm{~N} / \mathrm{A}$ & N/A & N/A & 0.03 & N/A & 0.02 \\
\hline $\begin{array}{l}\text { Scenario IV: Increasing Timber } \\
\text { Harvest }\end{array}$ & -0.03 & -0.05 & 0.04 & N/A & 0.02 & -0.05 & 0.01 & 0.01 \\
\hline $\begin{array}{l}\text { Scenario V: Decreasing Fuel } \\
\text { Number, Increasing Recreational } \\
\text { Forest Use and Fire Control Ability }\end{array}$ & N/A & N/A & N/A & -0.2 & 0.04 & -0.04 & -0.11 & 0.01 \\
\hline $\begin{array}{l}\text { Scenario VI: Increasing Fire } \\
\text { Control Ability and Timber } \\
\text { Harvest, Decreasing Clean Water } \\
\text { Supply Costs }\end{array}$ & -0.03 & -0.08 & N/A & N/A & 0.02 & -0.02 & 0.01 & 0.03 \\
\hline
\end{tabular}

From the figures above, when running each of the scenarios, there would be different changes happening on other components. The first 4 scenarios were happening by changing only one component; and Scenario V and VI were happening by changing three components at the same time. The outcomes of the 6 scenarios could be summed up in the table 8 with some important components that related to policy decisions on wildfire risk management.

These outcomes are basis on the perceptions from the students, which may really different from the perceptions and logics of the experts. From their group perception, since they had made as many as 75 connections for 14 components, the change rates on components may not extraordinarily high, but it is still showing some signs of the practical evidences for the scenarios.

All of the tested scenarios could be considered as a potential real practical policy to be made and achieve the management goals Basis on different management tasks, the decision-maker could be able to see through the scenario analysis results and pick up the best scenario as a potential decision to be made. For example, if the management task is to reduce the number of fires and reduce the risk of destructive fires, they could possibly consider Scenario I, reducing the number of fuels in the forest, as a future decision to be made, since from Scenario I, the number of fires and the risk of destructive fires had both been deductive the most. If the management task is to improving the economic impact, they could possibly pick up Scenario V, decreasing fuel number, increasing recreational forest use and fire control ability, as a possible future decision, because the economic impact had been increased the most through Scenario V, and also the risks of the destructive fires had been decreased, which also meet the needs of our research objective.

\section{Possible Contributions on Risk Perception Studies from FCM}

Was able to pool the insights from many people, clearly different scenarios, dynamic analysis, not too time consuming.
The above case study has shown the approaches of FCM when applied into the risk perception studies from a stakeholder group. The natural of FCM had been shown, including: being able to investigate the insights from multiple perspectives from many people, clearly different scenario tests, dynamic analysis, and efficient on analyzing process. These natural of FCM could be able to serve the purpose of risk perception studies well as identify the perceptions of risk, the factor affected to the risk and decision-making supports. The efficiency of data collection and analysis is relatively higher than most of the survey-based risk perception study methodologies. That is a huge advantage for FCM to possibly become a methodology for risk perception studies.

In general, the Fuzzy Cognitive Maps could not only provide the perceptions of the risk from individuals and the group, but also could provide a quick scenario prediction for management advising purposes. The scenarios could be set up follow the real-world situations or managerial problems, so that it could reflect as a model of the real situations, which could make the outcomes become more valuable as decisionmaking options. On the other hand, FCM could contain every related stakeholder group into the risk perception study, and let all of them to providing their perceptions. By analyzing the similarity within the same stakeholder group, and the differences among different stakeholder groups; the map could not only reflect the general perceptions of the group, but also could improve the risk communication among stakeholder groups by doing the map comparison. All of the major stakeholder groups - lay public, technological experts and the policy makers, could be benefit by knowing about how their stakeholder group is thinking and how the other groups are perceiving the same objective risks. The differences are not scary, but could be very instructive for making changes on the strategic level managerial problems.

In this way, Fuzzy Cognitive Maps could contribute to risk perception studies. 


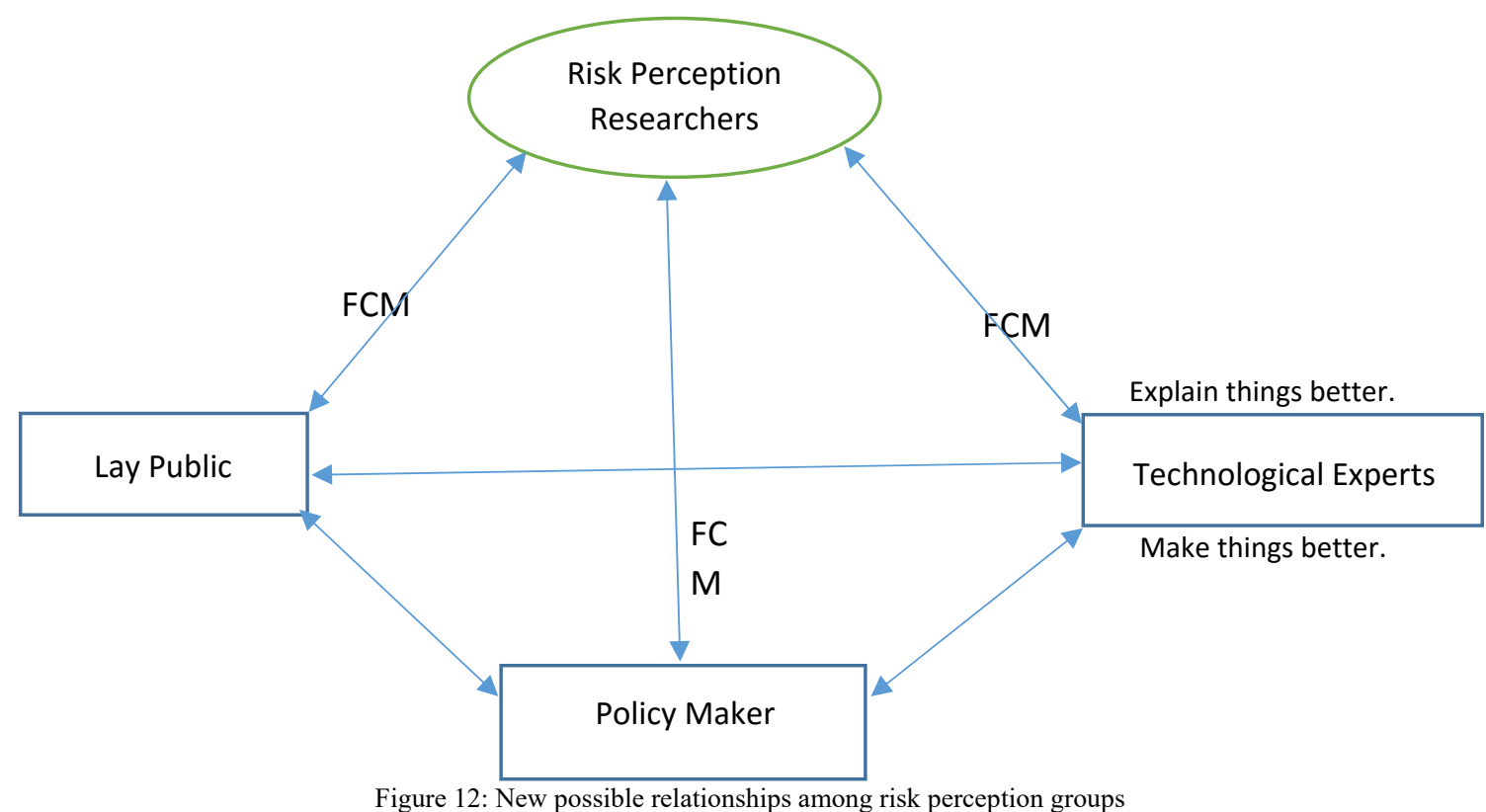

\section{DISCUSSION AND CONCLUSION}

By learning from existing risk perception studies, people who are involved into the risk event and risk perception studies all have their different roles. All the stakeholder groups' perceptions are valuable for the decision-making process on technology risk management. These different roles should be work together to make all the spots connected. From Figure 1, there are certain communication gaps among the 3 major stakeholder groups - lay public, technology experts, and policy makers, which are directly involved into the risk-related policy making process. They may not really talk with each other on any level or any decision-making stages. These also increase the problem of trust and knowledge differences among the stakeholder groups. One of the most important role for risk perception researchers, would be to build up these communications and ensure the communication could go through smoothly and effectively. The existing methodologies on risk perception studies are more or less have some short legs on building up the bridges for risk communication. To serve this purpose, Fuzzy Cognitive Maps could possibly be a way to provide the spot of the role for risk perception researchers, and close the ring of the research process. The gap of trust and knowledge differences between lay public and technological experts could be possibly solved by improving the communications. In order to reduce the perceived risk levels of the lay public, the technological experts may need to explain the technology better to the lay public, in order to let lay people knowing more and fearing less, with more trusts. Another way that the technological experts could pursue is to actually learn from the risk perceptions of lay public, even the policy makers, finding the new needs, and develop the technology or product in that way, to make things better, in order to possibly deducting the objective risks from their end.
The figure 12 could show a new relationship that might be look like in the future among the researchers and the 3 major stakeholder groups, which the two-way risk communications would need to be built.

\section{FUTURE WORKS}

In order to improving the risk communication and comparing different risk perceptions through different stakeholder groups, more efforts would be put on developing the map comparison approaches and map-combining approaches, which could also be helpful for making FCM not only a research tool, but also a practical decision-making tool for the managerial needs.

Also in the future, since the new needs for developing or finding a new risk perception study tool are mostly from the technological field, which they may need to make better decisions on business strategy and technology development strategies. If FCM could also be adopted into researches on how different stakeholder groups are perceiving the risk of a certain kind of technology, such as Internet of Things (IoT), and be able to run relevant scenarios or technology predictions, it could provide more evidence that FCM could be able to contribute to the risk perception studies.

\section{REFERENCES}

[1] R. H. Weber, "Internet of Things - New security and privacy challenges," Comput. Law Secur. Rev., vol. 26, no. 1, pp. 23-30, 2010.

[2] R. Roman, J. Zhou, and J. Lopez, "On the features and challenges of security and privacy in distributed internet of things," Comput. Networks, vol. 57, no. 10, pp. 2266-2279, 2013.

[3] Y.-K. Chen, "Challenges and opportunities of internet of things," 17th Asia South Pacific Des. Autom. Conf., pp. 383-388, 2012.

[4] J. Cooper and A. James, "Challenges for Database Management in the Internet of Things," IETE Tech. Rev., vol. 26, no. 5, p. 320, 2009.

[5] X. Luo, H. Li, J. Zhang, and J. P. Shim, "Examining multi-dimensional 
trust and multi-faceted risk in initial acceptance of emerging technologies: An empirical study of mobile banking services," Decis. Support Syst., vol. 49, no. 2, pp. 222-234, 2010.

[6] M. K. Chang, W. Cheung, and V. S. Lai, "Literature derived reference models for the adoption of online shopping," Inf. Manag., vol. 42, no. 4, pp. 543-559, 2005.

[7] A. Bieberstein, "An Investigation of Women's and Men's Perceptions and Meanings Associated with Food Risks," Wiesbaden: Springer Fachmedien Wiesbaden, 2014, pp. 25-62.

[8] P. Slovic, B. Fischhoff, and S. Lichtenstein, "Why study risk perception?," Risk analysis, vol. 2, no. 2. pp. 83-93, 1982.

[9] V. T. Covello, "The perception of technological risks: A literature review," Technol. Forecast. Soc. Change, vol. 23, no. 4, pp. 285-297, 1983.

[10] O. Renn, "The role of risk perception for risk management," Reliab. Eng. Syst. Saf., vol. 59, no. 1, pp. 49-62, 1998.

[11] L. Sj??berg, "Worry and risk perception," Risk Anal., vol. 18, no. 1, pp. 85-93, 1998.

[12] T. Rundmo, "Associations between risk perception and safety," Saf. Sci., vol. 24, no. 3, pp. 197-209, 1996.

[13] L. Frewer, "Risk Perception, Social Trust, and Public Parlicipation in Strategic Decision Making: Implications for Emerging Technologies," Ambio, vol. 28, no. 6, pp. 569-574, 1999.

[14] G. Elena and C. W. Johnson, "L Aypeople'S and Experts' Risk Perception of Cloud Computing Services," vol. 5, no. 4, pp. 1-19, 2015.

[15] M. Simon, S. M. Houghton, and K. Aquino, "Cognitive biases, risk perception, and venture formation: How individuals decide to start companies," J. Bus. Ventur., vol. 15, no. 98, pp. 113-134, 2000.

[16] W. Wang, J. Zhao, W. Zhang, and Y. Wang, "Conceptual Framework For Risk Propensity , Risk Perception , And Risk Behavior Of Construction Project Managers," no. September, pp. 165-174, 2015.

[17] P. E. Slovic, The perception of risk. Earthscan publications, 2000.

[18] P. Slovic and E. Peters, "Risk perception and affect. , 15(6), 322-325.," Curr. Dir. Psychol. Sci., vol. 15, no. 6, pp. 322-325, 2006.

[19] L. Sjöberg, "Perceived competence and motivation in industry and government as factors in risk perception," Soc. Trust Manag. risk, pp. 89-99, 1999.

[20] K. Bickerstaff, "Risk perception research: Socio-cultural perspectives on the public experience of air pollution," Environ. Int., vol. 30, no. 6, pp. 827-840, 2004.

[21] M. Horst, M. Kuttschreuter, and J. M. Gutteling, "Perceived usefulness, personal experiences, risk perception and trust as determinants of adoption of e-government services in The Netherlands," Comput. Human Behav., vol. 23, no. 4, pp. 1838-1852, 2007.

[22] A. E. Lobb, M. Mazzocchi, and W. B. Traill, "Modelling risk perception and trust in food safety information within the theory of planned behaviour," Food Qual. Prefer., vol. 18, no. 2, pp. 384-395, 2007.

[23] L. Sjöberg, "Principles of risk perception applied to gene technology," EMBO Rep., vol. 5, no. 1S, pp. S47-S51, 2004.

[24] P. Slovic, "Trust, Emotion, Sex, Politics, and Science: Surveying the Risk-Assessment Battlefield," Risk Anal., vol. 19, no. 4, pp. 689-701, 1999.

[25] M. Siegrist, H. Gutscher, and T. Earle, "Perception of risk: the influence of general trust, and general confidence," J. Risk Res., vol. 8, no. 2, pp. 145-156, 2005.

[26] Å. Boholm, "Comparative studies of risk perception: a review of twenty years of research," J. Risk Res., vol. 1, no. 2, pp. 135-163, 1998.

[27] L. Sjöberg, "Distal factors in risk perception," J. Risk Res., vol. 6, no. 3 , pp. $187-211,2003$.

[28] M. L. Finucane, P. Slovic, C. K. Mertz, J. Flynn, and T. a. Satterfield, "Gender, race, and perceived risk: The 'white male' effect," Health. Risk Soc., vol. 2, no. 2, pp. 159-172, 2000.
[29] L. Botterill and N. Mazur, "Risk \& risk perception: A literature review," no. 04, pp. 1-28, 2004.

[30] B. Fischhoff, P. Slovic, S. Lichtenstein, S. Read, and B. Combs, "How safe is safe enough? A psychometric study of attitudes towards technological risks and benefits," Policy Sci., vol. 9, no. 2, pp. 127$152,1978$.

[31] L. Wallquist, V. H. M. Visschers, and M. Siegrist, "Impact of knowledge and misconceptions on benefit and risk perception of CCS," Environ. Sci. Technol., vol. 44, no. 17, pp. 6557-6562, 2010.

[32] L. Whitmarsh, "Are flood victims more concerned about climate change than other people? The role of direct experience in risk perception and behavioural response," J. Risk Res., vol. 11, no. 3, pp. 351-374, 2008.

[33] F. Messner and V. Meyer, Flood damage, vulnerability and risk perception--challenges for flood damage research. Springer, 2006.

[34] P. Pavlou A., "Consumer Acceptance of Electronic Commerce: Integrating Trust and Risk with the Technology Acceptance Model," Int. J. Electron. Commer., vol. 7, no. 3, p. 34, 2003.

[35] H. J. Otway and P. D. Pahner, "ASSESSMENT," no. April, pp. 122 $134,1870$.

[36] K. L. Henwood, K. Anne Parkhill, and N. F. Pidgeon, "Science, technology and risk perception: From gender differences to the effects made by gender," Equal Oppor. Int., vol. 27, no. 8, pp. 662-676, 2008.

[37] S. Rippl, "Cultural theory and risk perception: a proposal for a better measurement," J. Risk Res., vol. 5, no. 2, pp. 147-165, 2002.

[38] D. Okrent, "Risk perception and risk management: on knowledge, resource allocation and equity," Reliab. Eng. Syst. Saf., vol. 59, no. 1, pp. 17-25, 1998.

[39] S. Jasanoff, "The political science of risk perception," Reliab. Eng. Syst. Saf., vol. 59, no. 1, pp. 91-99, 1998.

[40] P. Slovic and S. Lichtenstein, "Preference Reversals: A Broader Perspective," Am. Econ. Rev., vol. 73, no. 4, pp. 596-605, 1983.

[41] A. Tversky, P. Slovic, and D. Kahneman, "The causes of preference reversal," Am. Econ. Rev., pp. 204-217, 1990.

[42] J. Tixier, D. G. S. O, and D. Gaston, "Review of sixty two risk analysis methodologies of industrial plants," vol. 4, pp. 291-303, 2002.

[43] A. S. Akintoye and M. J. MacLeod, "Risk analysis and management in construction," Int. J. Proj. Manag., vol. 15, no. 1, pp. 31-38, 1997.

[44] A. Wildavsky and K. Dake, "Theories of risk perception: Who fears what and why?," Daedalus, vol. 119, no. 4, pp. 41-60, 1990.

[45] N. F. Pidgeon, "Risk assessment, risk values and the social science programme: why we do need risk perception research," Reliab. Eng. Syst. Saf., vol. 59, pp. 5-15, 1998.

[46] M. Siegrist and G. Cvetkovich, "Perception of hazards: The role of social trust and knowledge," Risk Anal., vol. 20, no. 5, pp. 713-719, 2000 .

[47] M. Wester-Herber, "Underlying concerns in land-use conflicts - The role of place-identity in risk perception," Environ. Sci. Policy, vol. 7, no. 2, pp. 109-116, 2004.

[48] L. Sjoberg, "Risk perception by the public and by experts: A dilemma in risk management," Hum. Ecol. Rev., vol. 6, no. 2, pp. 1-9, 1999.

[49] G. A. Moore, Crossing the Chasm: Marketing and Selling Disruptive Products to Mainstream Customers. HarperCollins, 2002.

[50] U. Özesmi and S. L. Özesmi, "Ecological models based on people's knowledge: a multi-step fuzzy cognitive mapping approach," Ecol. Modell., vol. 176, no. 1, pp. 43-64, 2004.

[51] A. Fairbrother and J. G. Turnley, "Predicting risks of uncharacteristic wildfires: Application of the risk assessment process," For. Ecol. Manage., vol. 211, no. 1-2, pp. 28-35, 2005.

[52] C. C. Hardy, "Wildland fire hazard and risk: Problems, definitions, and context," For. Ecol. Manage., vol. 211, no. 1-2, pp. 73-82, 2005.

[53] M. P. Thompson and D. E. Calkin, "Uncertainty and risk in wildland fire management: A review," J. Environ. Manage., vol. 92, no. 8, pp. 1895-1909, 2011. 